\title{
TaqMan DNA technology confirms likely overestimation of cod (Gadus morhua L.) egg abundance in the Irish Sea: implications for the assessment of the cod stock and mapping of spawning areas using egg-based methods
}

\author{
C. J. FOX, ${ }^{*}$ M. I. TAYLOR,†R. PEREYRA,† M. I. VILLASANA $\ddagger$ and C. RICO \\ *The Centre for Environment, Fisheries and Aquaculture Science, Pakefield Road, Lowestoft, Suffolk, United Kingdom, NR33 OHT, \\ †School of Biological Sciences, University of East Anglia, Norwich NR74 7TJ, łEstación Biológica de Doñana, CSIC Avenue Ma Luisa \\ s/n Pabellón del Perú, Apartado de correos 1050, 41013 Sevilla, Spain
}

\begin{abstract}
Recent substantial declines in northeastern Atlantic cod stocks necessitate improved biological knowledge and the development of techniques to complement standard stock assessment methods (which largely depend on accurate commercial catch data). In 2003, an ichthyoplankton survey was undertaken in the Irish Sea and subsamples of 'cod-like' eggs were analysed using a TaqMan multiplex, PCR (polymerase chain reaction) assay (with specific probes for cod, haddock and whiting). The TaqMan method was readily applied to the large number of samples $(n=2770)$ generated during the survey and when combined with a manual DNA extraction protocol had a low failure rate of $6 \%$. Of the early stage 'codlike' eggs (1.2-1.75 mm diameter) positively identified: $34 \%$ were cod, $8 \%$ haddock and $58 \%$ whiting. As previous stock estimates based on egg surveys for Irish Sea cod assumed that the majority of 'cod-like' eggs were from cod, the TaqMan results confirm that there was probably substantial contamination by eggs of whiting and haddock that would have inflated estimates of the stock biomass.
\end{abstract}

Keywords: fluorogenic 5' nuclease assay, gadoid identification, ichtyoplankton surveys, PCR, TaqMan

\section{Introduction}

Many cod (Gadus morhua) stocks in the northeast Atlantic are severely depleted because of overfishing combined with recent adverse environmental conditions (Beaugrand et al. 2003). For ecological research, changes in spawning grounds over time are an important consideration. Ichthyoplankton surveys can be a powerful tool to monitor such changes. Conservation efforts also rely on assessments of the size of the stock and virtual population analysis (VPA) is the most widely used assessment method in the northeast Atlantic. Unfortunately, for stocks at low abundance significant bias can be introduced into this method from misreporting of landings, undeclared discarding and

Correspendence: Dr Clive Fox, Fax: 441502 513865;

E-mail: c.j.fox@cefas.co.uk

C. J. Fox and M. I. Taylor contributed equally to the work presented. by the model assumption of constant natural mortality (Cotter et al. 2004). Ichthyoplankton surveys can be used as an additional stock assessment tool that is free from these underlying assumptions. In the annual egg production methods (AEPM), one uses ichthyoplankton surveys to estimate egg production over the spawning season. This information is combined with estimates of weight specific fecundity of the female fish, levels of atresia (degradation and absorption of oocytes prior to spawning), and the sex ratio of the population to produce an estimate of the spawning stock biomass.

In 1995, AEPM was applied to cod (Gadus morhua L.), plaice (Pleuronectes platessa L.) and sole (Solea solea L.) in the Irish Sea. For cod, the spawning stock biomass estimates generated were considerably in excess of those derived from VPA (Armstrong et al. 2001). One potential reason for this discrepancy may have been the difficulty in unambiguously identifying the early stage eggs of cod from those of other species with similar appearance and overlapping size 
ranges, in particular haddock (Melanogrammus aeglefinus) and whiting (Merlangius merlangus). As only small quantities of mature haddock were being caught in the area at the time, it was assumed that the majority of eggs between 1.2 and $1.75 \mathrm{~mm}$ diameter and lacking oil globules were those of cod (Fox et al. 1997; Armstrong et al. 2001). Since then, the amount of mature haddock in the Irish Sea has increased and the assumption that the majority of 'cod-like' eggs are truly cod is no longer tenable (Dickey-Collas et al. 2003).

In 2000, the AEPM was repeated and iso-electric focusing (IEF) was used to identify subsamples of eggs to species (Mork et al. 1983). In practice, this method had a number of disadvantages which presented practical problems at sea and possibly led to a relatively high proportion (36\%) of failed reactions (Heffernan et al. 2004). Despite the high failure rates, the data suggested that the eggs contained a significant fraction of species other than cod.

In an attempt to overcome the problems with IEF, we have developed a highly specific and sensitive DNA-based egg identification method (Taylor et al. 2002). In this study we report the results from the first field application of this method and evaluate the relative advantages/disadvantages of the TaqMan approach compared to IEF. We also address the hypothesis that misidentification of cod eggs could have contributed to the apparently elevated spawning stock biomass estimates generated by AEPM.

\section{Materials and methods}

Field sampling

A single survey was undertaken using research vessel (RV) Corystes between 18 February and 4 March 2003 following the design employed in 1995 and 2000 (Armstrong et al. 2001). At each station, plankton were collected using a Gulf VII high-speed sampler deployed in a double-oblique manner to within $3 \mathrm{~m}$ of the seabed at a towing speed of $3-$ 4.5 knots (Nash et al. 1998). On shallow stations, multiple oblique tows were undertaken to ensure that a sufficient volume of water was filtered. Upon recovery, the plankton sample was transferred into a jug and kept cool on ice. Aliquots of the sample were examined in Pyrex pie dishes and 'cod-sized' eggs removed using wide-bored pipettes. These eggs were transferred into drops of seawater on a Petri dish and measured using an interactive image-analysis system (PISCES, Perceptive Instruments). Eggs falling within the size range $0.9-1.75 \mathrm{~mm}$ diameter and not possessing oil globules or other characteristic features (such as the segmented yolk of sprat eggs, Sprattus sprattus) were classified as 'cod-like'. These eggs were assigned a developmental stage according to Thompson \& Riley (1981) and transferred into individually labelled tubes containing $1.5 \mathrm{~mL}$ of ethanol. Shipboard sorting was continued until up to 100 eggs had been removed from the sample. The remainder of the plankton sample was then fixed in $4 \%$ formalin [ $4 \%$ formaldehyde in distilled water buffered with $2.5 \%$ sodium acetate trihydrate $(\mathrm{w} / \mathrm{v})]$. Fish eggs and larvae were subsequently sorted, identified and enumerated on the basis of size and appearance (Russell 1976). All eggs larger than $1.2 \mathrm{~mm}$ in diameter were identified, measured and assigned to development stage. On stations where there were very high abundance of smaller eggs, a Folsom splitter was used for subsampling (UNESCO 1968).

\section{Application of TaqMan probes to presorted eggs}

The technical details of the TaqMan method for distinguishing eggs of cod, haddock and whiting are described in Taylor et al. (2002). In summary, the technique is a polymerase chain reaction (PCR) monitored in real time by the release of up to three fluorogenic dyes with unique emission spectra in a multiplex reaction. Each dye is linked to a species-specific probe and a quencher so that the release of the dye from the quencher results in an increase in detection signal proportional to the rate of amplification for that specific probe.

Total DNA was extracted from individual eggs in 96well plates using Proteinase $\mathrm{K}$ digestion and either the Bilatest Magnetic Bead Extraction Kit (Bilatec AG) running on a Roboseq 4204 S robot (MWG), or salt precipitation using a manual protocol modified from Aljanabi \& Martinez (1997). PCR was undertaken using $1 \mu \mathrm{L}$ (c. $50 \mathrm{ng}$ ) of extracted DNA per well amplified with $200 \mathrm{~nm}$ of each species-specific probe (COD-P, FAM labelled, HAD-P, TET labelled, and WHI-P, VIC labelled), $300 \mathrm{~nm}$ of the GAD-F and GAD-R primers, $8.3 \mu \mathrm{L}$ of TaqMan Universal PCR Master Mix (ROX passive reference) (Applied Biosystems) and $4.9 \mu \mathrm{L}$ tissue culture $\mathrm{H}_{2} \mathrm{O}$ (Sigma). Plates were run under real time conditions on three dye layers with eight no template controls (NTCs) and three positives (DNA extracted from eggs from hatchery cod, haddock and whiting) per 96-well plate. The assay was run using the default cycling conditions. Post PCR, the results were analysed using the sequence detection software version 1.71 (Applied Biosystems). The $\Delta R_{n}$ values for each cycle and dye layer were then exported to MS Excel, and processed further as described in Taylor et al. (2002).

Samples which had been manually extracted and failed to react with the TaqMan probes were amplified using universal teleost cytochrome B primers GLU (L)-TGACTTGAAGAACCAC/TCGT TG-3' (Palumbi 1996) and CB2-(H)AAAC TGCAGCCCCTCAGAATGATAT T TGTCCTCA-3' (Kocher et al. 1989). PCR was performed in an MJ Research PTC-200 thermal-cycler under the following conditions: $94{ }^{\circ} \mathrm{C}$ for $120 \mathrm{~s}$; followed by 30 cycles of $94^{\circ} \mathrm{C}$ for $30 \mathrm{~s}, 47^{\circ} \mathrm{C}$ for $30 \mathrm{~s}, 72{ }^{\circ} \mathrm{C}$ for $45 \mathrm{~s}$; followed by $72{ }^{\circ} \mathrm{C}$ for $10 \mathrm{~min}$. Ten $\mu \mathrm{L}$ reaction mixes consisted of $1 \mu \mathrm{L}$ (c. $20 \mathrm{ng}$ ) template DNA, $0.5 \mu \mathrm{m}$ of each primer, $5 \mu \mathrm{L}$ of $2 \times$ PCR Master Mix (ABGene), 
and $2 \mu \mathrm{L} \mathrm{H}_{2} \mathrm{O}$. PCR products were resolved on $1.2 \%$ agarose gels run in $0.5 \times$ TBE buffer and stained with ethidium bromide. Samples that produced amplification products were classed as 'null' reactions, i.e. not cod, haddock or whiting but another species for which specific probes have not yet been developed. Samples that produced no amplification products were classified as 'failed extractions'.

\section{Statistical treatment of data}

The accuracy of the subsampling undertaken at sea was assessed by comparison of egg diameter and developmental stage frequency distributions in the subsamples and in the subsequent laboratory analyses of the remaining formalinfixed eggs. Second, the reliability of the TaqMan egg identification method was assessed by consideration of percentages of samples positively identified and producing 'null' or 'failed' reactions. The data were then filtered to include only eggs at the early developmental stage (stage I). At the water temperatures recorded during the ichthyoplankton survey $\left(4-8{ }^{\circ} \mathrm{C}\right)$, cod eggs take between 3.5 and 5 days to develop through the end of stage I so the location of stage I eggs will be close to site of spawning ( Thompson \& Riley 1981). At each sampling location, the number of 'cod-like' eggs in the laboratory-sorted portion of the plankton sample was apportioned between cod, haddock, whiting and other species on the basis of the ratio determined from the TaqMan analyses of the presorted eggs from that location.

\section{Results}

On stations with low to medium abundance of 'cod-like' eggs (<500 eggs), we were usually able to presort for subsequent TaqMan analysis more than 20\% of the eggs from the total available. On stations where eggs were very abundant, the percentage presorted varied between $1 \%$ and $10 \%$ of the eggs available. The frequency distribution of developmental stages in the presorted subsamples and in the remainder of the total plankton sample was in good agreement although there may have been a slight bias towards presorting too many stage $\mathrm{V}$ eggs (percentages presorted compared with percentage of stages in the remainder of plankton sample: stage I, $43.4 \%$ cf. $44.1 \%$; stage II $23.4 \%$ cf. $28.4 \%$; stage III $23.8 \%$ cf. $20.2 \%$; stage IV $7.1 \%$ cf. $6.6 \%$; stage V $2.4 \%$ cf. $0.7 \%$ ). These results support the conclusion that presorting at sea was capable of producing a representative subsample from the total eggs present.

The majority of eggs lacking oil globules collected in the survey were smaller than $1.0 \mathrm{~mm}$ diameter and were most likely produced by dab (Limanda limanda) and flounder (Platichthys flesus). The size range of eggs positively identified as cod by the TaqMan assay was $1.17-1.63 \mathrm{~mm}$ (95 percentiles of size distribution) and was 1.17-1.62 mm for haddock. These ranges were in good agreement with those quoted in Russell (1976). Using a lower limit of $1.2 \mathrm{~mm}$ diameter as a cut-off for staging eggs in the formalin-fixed portion of the sample would have encompassed $97 \%$ of cod eggs present and $98 \%$ of haddock. The maximum size of positively identified whiting eggs was slightly greater than literature estimates, 95\% of the observations lay within the range 0.97-1.41 mm (Russell 1976 quotes a min-max range of $0.97-1.32 \mathrm{~mm}$ ).

The results of TaqMan analysis of robotically and manually extracted eggs are given in Table 1 . An unacceptably high proportion of eggs extracted using the robotic procedure failed to react with TaqMan probes (27\%). In the majority of cases this appeared to be caused by the robot having failed to deliver reagents to the correct wells on the plate, which caused high levels of cross-contamination and irrecoverable loss of the samples. Because of this, the robotic DNA extraction was replaced with a manual procedure. When the remaining samples were extracted using the manual protocol, the failure rate dropped to $6 \%$. Failure rates were not related to egg development stage indicating that the TaqMan PCR probes are sufficiently sensitive to identify even the earliest stage eggs that contain low levels of DNA. The occurrence of failures was also unrelated to

Table 1 Numbers of eggs presorted and genetically analysed and success rates of TaqMan species identification. Includes all eggs collected (0.9-1.75 mm diameter)

\begin{tabular}{|c|c|c|c|c|c|c|c|}
\hline Stage & $\begin{array}{l}\text { Number } \\
\text { eggs - } \\
\text { robotic DNA } \\
\text { extraction }\end{array}$ & $\begin{array}{l}\text { Number } \\
\text { eggs - } \\
\text { manual DNA } \\
\text { extraction }\end{array}$ & $\begin{array}{l}\text { Failed } \\
\text { TaqMan - } \\
\text { robotic DNA } \\
\text { extraction } \\
(\%)\end{array}$ & $\begin{array}{l}\text { Positively identified } \\
\text { by TaqMan - } \\
\text { robotic DNA } \\
\text { extraction } \\
(\%)\end{array}$ & $\begin{array}{l}\text { Failed } \\
\text { TaqMan - } \\
\text { manual DNA } \\
\text { extraction } \\
(\%)\end{array}$ & $\begin{array}{l}\text { Null reaction } \\
\text { TaqMan - } \\
\text { manual DNA } \\
\text { extraction } \\
(\%)\end{array}$ & $\begin{array}{l}\text { Positively identified } \\
\text { TaqMan - } \\
\text { manual DNA } \\
\text { extraction } \\
(\%)\end{array}$ \\
\hline I & 608 & 563 & 24.6 & 75.4 & 7.3 & 5.5 & 87.2 \\
\hline II & 238 & 428 & 27.3 & 72.7 & 4.9 & 4.9 & 90.2 \\
\hline III & 210 & 463 & 30.0 & 70.0 & 5.6 & 5.0 & 89.4 \\
\hline IV & 98 & 107 & 35.7 & 64.3 & 6.5 & 6.5 & 86.9 \\
\hline $\mathrm{V}$ & 21 & 34 & 38.1 & 61.9 & 2.9 & 0.0 & 97.1 \\
\hline Total & 1174 & 1595 & 27.2 & 72.8 & 6.0 & 5.2 & 88.8 \\
\hline
\end{tabular}



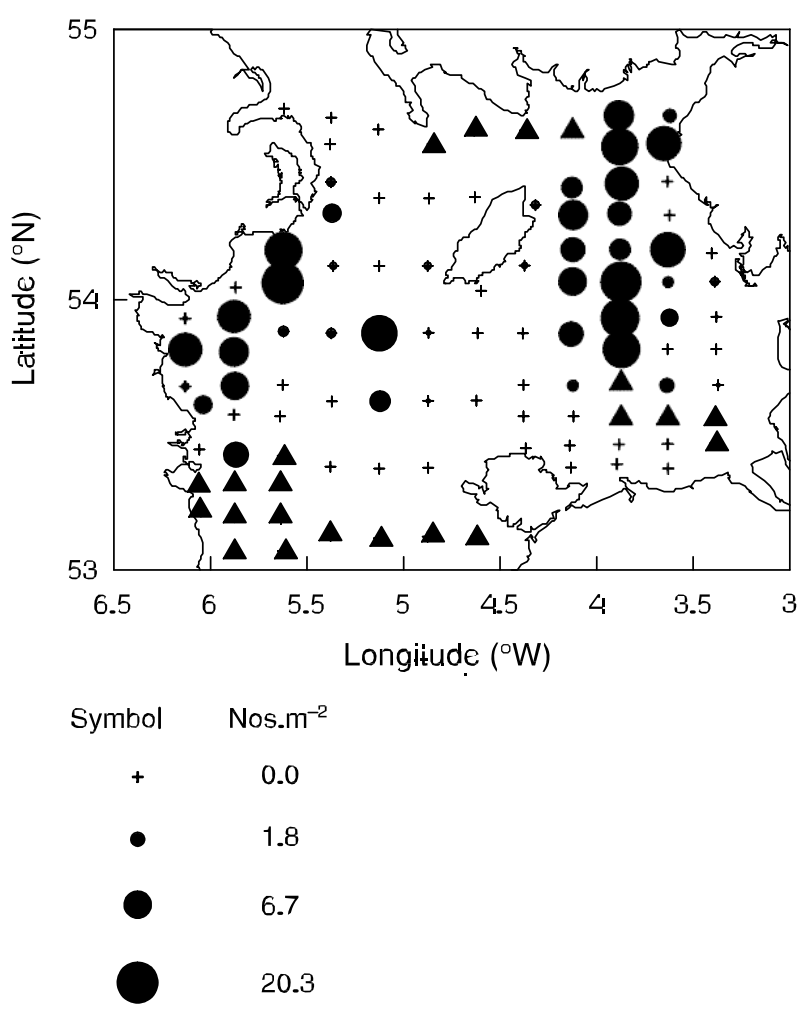

Symbols on $\log _{\mathrm{e}}$ scale

Fig. 1 Chart showing the distribution of stage I cod eggs based on number of 'cod-like' eggs in the plankton samples raised by the proportion of positively identified cod eggs by TaqMan. The data are expressed as nos $\mathrm{m}^{-2}$ sea surface, bubble diameter represents abundance following a logarithmic transformation. Solid triangle symbols indicate stations where there were insufficient genetic results to apply proportional raising.

sample number within each station (C.J. Fox, unpublished). This supports the view that failures were not related to handling time on-board the research vessel and we conclude that sample collection and presorting at sea does not cause significant mitochondrial DNA degradation (at least within the 80 min taken to sort 100 eggs).

Early stage 'cod-like' eggs $(>1.2 \mathrm{~mm})$ were most abundant in areas close to the Irish coast, around the Isle of Man and in the eastern Irish Sea. Based on positive identification by TaqMan (excludes failed extractions), $58 \%$ of these were whiting, $34 \%$ were cod and $8 \%$ were haddock. The distribution of positively identified cod eggs was generally similar to the distribution of 'cod-like' eggs but cod were absent off the North Wales coast (Fig. 1). Stage I haddock eggs were confined to a few stations off the Irish coast and to the southeast of the Isle of Man (Fig. 2). The TaqMan analyses showed that the majority of 'cod-like' eggs sampled were in fact whiting. The eggs of this species were widely distributed across the shallower stations. The loss of several complete plates of samples (during robotic processing)
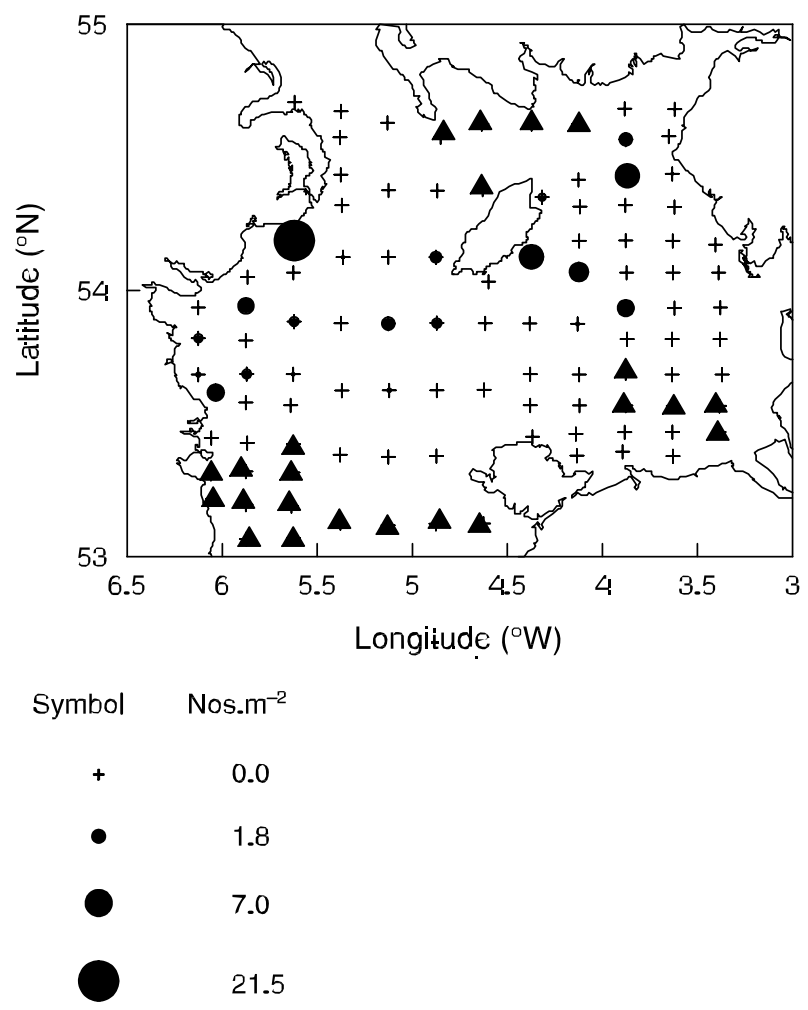

Symbols on $\log _{\mathrm{e}}$ scale

Fig. 2 Chart showing the distribution of stage I haddock eggs based on number of 'cod-like' eggs in the plankton samples raised by the proportion of positively identified haddock eggs by TaqMan. Key as Fig. 1.

prevented estimation of egg abundance by species at a number of stations. However, these largely coincided with stations with low overall numbers of 'cod-like' eggs and it is not anticipated that their absence would markedly alter the resulting species-specific distribution patterns.

\section{Discussion}

Three key outcomes have arisen from this study. First, around one-third of the 'cod-like' eggs analysed were positively identified as cod. Second, early stage haddock eggs were identified proving that a spawning stock now exists in the Irish Sea. Third, the TaqMan technique can be readily applied to the large numbers of samples collected during ichthyoplankton surveys with good reliability in egg identification (failure rate of $6 \%$ using manual DNA extraction procedure).

These results demonstrate that the size fraction of eggs previously assumed to be mostly cod will be contaminated with a substantial proportion of whiting as well as haddock 
eggs. Without the application of molecular identification, the assumption that all 'cod-like' eggs are cod will lead to inaccurate spawning maps and inflate spawning stock biomass estimates made by egg production methods. The present results, along with those of Heffernan et al. (2004), show that at least part of the discrepancy between the stock biomass estimate produced from the 1995 AEPM and from fishery-dependent methods (e.g. VPA) was probably because of egg misidentification (Armstrong et al. 2001; Armstrong \& Dickey-Collas 2002).

Ideally, any species identification method should be capable of positively identifying close to $100 \%$ of the samples analysed. This removes any element of doubt and simplifies the apportioning of species ratios determined on subsamples. In the Irish Sea, a few species in addition to cod, haddock and whiting produce eggs with overlapping size ranges and similar appearance. Based on IEF results (Heffernan et al. 2004) and the occurrence of larvae (Fox et al. 1997; Bunn \& Fox 2004), these include: lemon sole (Microstomus kitt), witch (Glyptocephalus cynoglossus), pollack (Pollachius pollachius), saithe (Pollachious virens), bib (Trisopterus luscus) and Norway pout (Trisopterus esmarkii). Because of high development costs, we have so far only produced specific TaqMan probes for the three main commercial species. Eggs of other species can thus produce a null reaction with the TaqMan probes but by re-amplifying with universal teleost primers we were able to distinguish these samples from those where DNA extraction had failed or DNA had degraded. The percentage occurrence of these other species in the Irish Sea was relatively low (c. $5 \%$ based on eggs of all sizes which had been manually extracted, failed to react with TaqMan probes and were successfully re-amplified with universal primers) but in other sea areas they could form a larger proportion of eggs sampled. The capacity to expand the number of species that can be identified in a multiplex TaqMan reaction is currently limited by the number of wavelength specific dyes available.

Surveys for mapping spawning locations should ideally cover the whole spawning season. Because this was a demonstration project and timing was constrained by ship availability only a single survey was undertaken. It is thus not possible to describe the temporal extent of spawning from these data. Historical data, based on the appearance of late stage eggs and larvae, suggest that the peak of cod spawning occurs from early to the middle of March in the western Irish Sea, and a little later in the eastern area (Brander 1994; Fox et al. 1997; Bunn \& Fox 2004). The 2003 survey was therefore probably too early to hit the peak but coincided with the onset of cod spawning in both areas.

Comparing the application of DNA-based and IEF identification to ichthyoplankton surveys: the DNA-based method has greater sensitivity and reliability [comparing results in this study with those in Heffernan et al. (2004)]; samples for
DNA-based analyses can be stored at room temperature whilst material for IEF must be kept frozen (ideally at $-80{ }^{\circ} \mathrm{C}$ but at $-20^{\circ} \mathrm{C}$ for short periods) which can prove problematic at sea and when transporting samples between laboratories; the main disadvantage of the DNA-based method is cost. A significant limitation of applying both techniques to ichthyoplankton surveys is the requirement to presort target eggs from the bulk of the plankton at sea in order to preserve them in a manner that does not degrade DNA (or protein for IEF). This is time consuming and only feasible under reasonably calm sea conditions. Using DNA-based molecular methods, it may be possible to overcome this problem as there are reports of successful PCR from formalin-fixed samples (France \& Kocher 1996; Shedlock et al. 1997; Chase et al. 1998; Kirby \& Reid 2001). In contrast, formalin renders material totally unsuitable for IEF. Recent success with the use of monoclonal antibodies with formalin-fixed eggs has also been reported (Hiroishi et al. 2004).

In conclusion, the TaqMan method proved suitable for application to the large numbers of samples generated during an ichthyoplankton survey. Early stage haddock eggs were positively identified demonstrating that a spawning stock exists in the Irish Sea. The TaqMan analysis also showed that the majority of 'cod-like' eggs sampled were from whiting supporting the idea that egg misidentification was one potential reason for previous elevated estimates of stock biomass using egg production methods in this region. Wider application of molecular-based identification methods in ichthyoplankton surveys will significantly increase the accuracy of spawning maps and stock assessments for species producing eggs that cannot be separated using classical methods.

\section{Acknowledgements}

The authors wish to acknowledge the hard work of all seagoing staff involved in this program and the crew and officers of RV Corystes. We would also like to acknowledge the dedication of the CEFAS plankton sorting team who analysed the bulk plankton samples. Research vessel time was funded by Defra (Department of Environment and Rural Affairs) whilst sample analyses were supported through Defra project M0151 (Field trial of genetic probes for identifying gadoid eggs).

\section{References}

Aljanabi SM, Martinez I (1997) Universal and rapid salt-extraction of high quality genomic DNA for PCR-based techniques. Nucleic Acids Research, 25, 4692-4693.

Armstrong MJ, Connolly P, Nash RDM et al. (2001) An application of the annual egg production method to estimate spawning biomass of cod (Gadus morhua L.), plaice (Pleuronectes platessa L.) and sole (Solea solea L.) in the Irish Sea. ICES Journal of Marine Science, 58, 183-203.

Armstrong MJ, Dickey-Collas M (2002) Development and validation of egg-production based biomass estimates, using cod and plaice stocks in the Irish Sea. Contract Final Report - Commission of 
the European Communities, Directorate General for Fisheries, Contract 98/090, Department of Agriculture and Environmental Science. Beaugrand G, Brander KM, Lindley AJ, Souissi S, Reid PC (2003) Plankton effect on cod recruitment in the North Sea. Nature, 426, 661-664.

Brander K (1994) Spawning and life history information for North Atlantic cod stocks. International Council for the Exploration of the Sea (ICES), Cooperative Research Report, 205, 150.

Bunn N, Fox CJ (2004) Spring plankton surveys of the Irish Sea in 2000: hydrography and the distribution of fish eggs and larvae. Science Series Data Report, No. 41, Centre for Environment, Fisheries and Aquaculture Science.

Chase MR, Etter RJ, Rex MA, Quattro JM (1998) Extraction and amplification of mitochondrial DNA from formalin-fixed deepsea molluscs. Biotechniques, 24, 243-247.

Cotter AJR, Burt L, Paxton CGM et al. (2004) Are stock assessment methods too complicated? Fish and Fisheries, 5, 235-254.

Dickey-Collas M, Armstrong MJ, Officer RA et al. (2003) Growth and expansion of haddock (Melanogrammus aeglefinus L.) stocks to the west of the British Isles in the 1990s. ICES Marine Science Symposium, 219, 271-282.

Fox CJ, Dickey-Collas M, Winpenny AJ (1997) Spring plankton surveys of the Irish Sea in 1995: the distribution of fish eggs and larvae. Science Series Technical Report, No. 104, Centre for Environment, Fisheries and Aquaculture Science.

France SC, Kocher TD (1996) DNA sequencing of formalin-fixed crustaceans from archival research collections. Molecular Marine Biology and Biotechnology, 5, 304-313.

Heffernan OA, Danilowicz BS, Milligan SP (2004) Determination of species-specific spawning distributions of commercial finfish in the Irish Sea using a biochemical protein-based method. Marine Ecology Progress Series, in press.

Hiroishi S, Yuki Y, Yuruzume E et al. (2004) Identification of formalin- preserved eggs of red sea bream (Pagrus major) (Pisces: Sparida) using monoclonal antibodies. Fisheries Bulletin, 102, 555-560.

Kirby RR, Reid PC (2001) PCR from the CPR offers a historical perspective on marine population ecology. Journal of the Marine Biological Association of the United Kingdom, 81, 339-340.

Kocher TD, Thomas WK, Meyer A et al. (1989) Dynamics of mtDNA evolution in animals: amplification and sequencing of conserved primers. Proceedings of the National Academy of Sciences of the United States of America, 86, 6196-6200.

Mork J, Solemdal P, Sundes G (1983) Identification of marine fish eggs: a biochemical genetics approach. Canadian Journal of Fisheries and Aquatic Sciences, 40, 361-369.

Nash RDM, Dickey-Collas M, Milligan SP (1998) Descriptions of the Gulf VII/PRO-NET and MAFF/Guildline unencased high-speed plankton samplers. Journal of Plankton Research, 20, 1915-1926.

Palumbi SR (1996) Nucleic acids II. The polymerase chain reaction. In: Molecular Systematics (eds Hillis DM, Moritz C, Mable BK), pp. 205-247. Sinauer, Sunderland, Massachusetts.

Russell FS (1976) The Eggs and Planktonic Stages of British Marine Fishes. Academic Press, London.

Shedlock AM, Haygood MG, Pietsch TW, Bentzen P (1997) Enhanced DNA extraction and PCR amplification of mitochondrial genes from formalin-fixed museum specimens. BioTechniques, 22, 395-399.

Taylor MI, Fox CJ, Rico I, Rico C (2002) Species-specific TaqMan probes for simultaneous identification of cod (Gadus morhua L.), haddock (Melanogrammus aeglefinus L.) and whiting (Merlangius merlangus L.). Molecular Ecology Notes, 2, 599-601.

Thompson BM, Riley JD (1981) Egg and larval development studies in the North Sea cod (Gadus morhua L.). Rapports et Procès-verbaux des Réunions Conseils International pour l'Exploration de la Mer, 178, 553-559.

UNESCO (1968) Zooplankton Sampling. United Nations Educational, Scientific and Cultural Organization, Paris. 